\title{
Psychometric characteristics of the Portuguese version of the Preschool Pediatric Symptom Checklist for children aged 18 to 60 months
}

\author{
Bruno Rocha 1 iD 1,2 Cristina Nunes 3 \\ ${ }^{1}$ University of Algarve \\ ${ }^{2}$ USF Ria Formosa \\ ${ }^{3}$ Department of Psychology and Educational Sciences of University of Algarve
}

\begin{abstract}
Early detection of social-emotional and behavioral problems in children is important, because this anticipation allows for more effective intervention. Therefore, this quantitative, cross-sectional and instrumental study examined the factor structure, internal consistency, and various other psychometric properties of the Portuguese version of the Preschool Pediatric Symptom Checklist (PPSC). The participants were 398 Portuguese parents who completed the PPSC and a sociodemographic questionnaire. The PPSC, consisting of 18 items, measures the social-emotional statuses of children from the ages of 18 to 60 months. Three competing models (the unifactorial, 3-factorial and 4-factorial models) were tested as regards the PPSC's factor structure using a confirmatory factor analysis. Our findings suggest that the original unifactorial scale of the PPSC is the most suitable in terms of the Portuguese version of this measure. The use of the PPSC in primary healthcare, its diagnostic accuracy, and children's related socialemotional adjustment factors are then discussed.
\end{abstract}

\section{Keywords: Confirmatory factor analysis; Infant; Pediatric symptoms; Preschool; Psychometrics.}

Características psicométricas da versão portuguesa da Lista de Sintomas Pediátricos em Idade PréEscolar para crianças dos 18 aos 60 meses: A deteção precoce de problemas socio-emocionais e comportamentais nas crianças é importante, na medida em que essa antecipação possibilita uma intervenção mais eficaz. Este estudo quantitativo, transversal e instrumental pretendeu analisar a estrutura fatorial, a consistência interna e outras propriedades psicométricas da versão portuguesa da Lista de Sintomas Pediátricos em Idade Pré-Escolar (PPSC). Participaram 398 pais portugueses através do questionário PPSC e de um questionário sociodemográfico. O PPSC avalia através de 18 itens problemas socio-emocional de crianças com idades compreendidas entre os 18 e os 60 meses. Foram testados três modelos diferentes do PPSC (unifatorial, três fatores e quatro fatores) através da análise fatorial confirmatória. Os resultados sugerem que a versão unifatorial original do PPSC, sua versão portuguesa, é a mais adequada. É discutido o uso do PPSC nos cuidados de saúde primários, a sua precisão diagnóstica e os fatores relacionados com o ajustamento socio-emocional das crianças.

Palavras-chave: Análise fatorial confirmatória; Crianças; Pré-escolar; Psicometria; Sintomas pediátricos.

The early detection of social-emotional challenges faced by children is extremely important for ensuring their healthy development and overall family wellbeing (Alakortes et al., 2017; Silva et al., 2019). Children with unmet social-emotional needs tend to experience difficulties in their relationships with their parents and their peers, at school, and in their development of prosocial behaviors (Linberg et al., 2017; Ortiz \& Barnes, 2018). Internalized and externalized challenges in children are often related to stressful life events and an unstable family climate. Children with lower cognitive and adaptive skills often have higher levels of internalized behaviors (Mitchell \& Hauser-Cram, 2009). In one American sample, single parenthood was the only significant factor found in connection with unhealthy child behaviors. Parent depression and the overall cultural context also emerged as possible predictors for externalized behaviors (Tichovolsky, 2011).

A study involving one year old American children found that $32 \%$ of them experienced socialemotional difficulties related to their behaviors, which then interfered with their family activities (BriggsGowan et al., 2001). In the USA, 35\% of children aged between 18 and 22 months experience behavioral

${ }^{1}$ Correspondence address: Bruno Rocha, Rua António Gedeão, 33, 8700-280, Olhão, Portugal. E-mail: bmp.rocha@gmail.com. This work was funded by national funds through FCT - Fundação para a Ciência e a Tecnologia - as part the project CIP - Ref 
difficulties, with $26 \%$ of them showing deficits in their social-emotional competencies (Peralta-Carcelen et al., 2017). Parents' perceptions of these difficulties tend to be relatively low, with only $3.5 \%$ to $7 \%$ of them showing concern for their child's social-emotional/behavioral difficulties (Alakortes et al., 2017; BriggsGowan et al., 2001). In one German sample involving four year old children, $12.6 \%$ of them presented elevated internalizing symptoms, with $44.3 \%$ showing moderate ones (Klein et al., 2019). The prevalence of preschool-aged children with behavioral difficulties was found to be $4.8 \%$ in Denmark, $8.6 \%$ in Germany, and $8.8 \%$ in Scotland (Sim et al., 2019). In Spain, some studies have found that, in pediatric primary care consultations, $24 \%$ of mothers' concerns were about their children's behavioral difficulties (Nunes \& Ayala, 2011; 2013). The importance of predicting developmental and behavioral challenges faced by children means that construct measures anticipating potential exposure factors and developmental issues are needed (Alakortes et al., 2017; Silva et al., 2019).

The Portuguese version of the Preschool Pediatric Symptom Checklist (PPSC) was designed to be a simple and reliable measure that screens for social-emotional challenges in children aged 18 to 60 months. This measure was created to be both simple and useful in pediatric consultations. This scale was developed in Boston, USA, and is part of a bigger project called the "Survey of Wellbeing of Young Children" (SWYC), which is a measurement designed for use in pediatric primary healthcare (Sheldrick et al., 2012).

The SWYC is a North American survey that was constructed in 2011 and validated in 2013, which allowed parents to report on their children's development from the ages of one to 60 months old (Sheldrick et al., 2012). This is a simple and freely available questionnaire, which was recognized by the American Academy of Pediatrics for use in analyzing a child's developmental status (Perrin et al., 2016).

The construction of this scale is a result of a review of other measures already available in the literature, complemented by clinical experience, and which was revised by both parents and experts in its measuring of children's development across various dimensions. One of its advantages is that it is simple to use and is open access (Abidin, 1995; Briggs-Gowan \& Carter, 1998; Finello \& Poulsen, 2018; Greenspan, 2004; Jahromi et al., 2013; Moreira et al., 2019; Sheldrick et al., 2012; Squires et al., 1995).

We selected the PPSC because of its simplicity, clinical validity, and objectivity. The PPSC has been translated into 10 languages, including Brazilian Portuguese. Most of these reports, however, only explain the translation process and not the validation one, except for that by the Brazilian Portuguese translation as presented by Moreira et al. (2019). In the present study, we have only translated the PPSC, which is one part of the multifaceted SWYC survey.

The original PPSC consists of an 18-item questionnaire that is divided into four subscales that measure the following domains of child development: "Internalizing," "Externalizing," "Attention challenges," and "Parent challenges." The authors have also suggested a trifactorial scale consisting of 12 items, without those covering the "Parent challenges" subscale, as it has better psychometric proprieties.

The "Internalizing" subscale asks about children's internal manifestations of emotions, including feeling nervous, sad, or unhappy, or if they are experiencing difficulties in adapting to routine changes. Yoon et al. (2017) stated that children's internalizing disorders tend to remain stable over time and that they are related with child neglect, exposure to intimate partner violence, an insecure caregiver-child attachment style, and caregiver mental health. The "Externalizing" subscale measures a child's external manifestations of their emotions, such as breaking things on purpose or being aggressive. Mingebach et al. (2018) refers to externalizing behavioral disorders as a major reason for children's referral to mental health evaluations. The "Attention problems" subscale covers concepts related to children's difficulties in paying attention, sitting still, or staying focused on one activity. Attention problems in children often appear during the first years of their life, which then remain as lifelong difficulties. Therefore, early identification and intervention related to these challenges are beneficial to children's development and their lifelong mental health (Halperin \& Marks, 2019).

The PPSC was utilized by the authors as a unifactorial 18-item model. The items were each rated along a 3-point frequency scale, measured as follows: 0 for "Not at All," 1 for "Somewhat," and 2 for "Very Much." A total score of nine or higher in the PPSC indicates that a child is "at risk" and needs further evaluation (Sheldrick et al., 2012). The purpose of the PPSC is to provide an early identification of relevant social-emotional difficulties in children aged 18 to 60 months in order to then conduct further analyses as needed.

The internal consistency reliability statistics of the original PPSC were $\alpha=.88$ in the primary sample and $\alpha=.86$ in the replication sample. The final factor structure of the 3-factor model displayed an adequate fit, both in the primary (RMSEA $=.04, \mathrm{CFI}=.98, \mathrm{TLI}=.98)$ and the replication samples $(\mathrm{RMSEA}=.04, \mathrm{CFI}=$ .97 , TLI = .96). However, the interpretation of the unifactorial model was supported, as it had lower fit values (RMSEA $=0.08 ; \mathrm{CFI}=0.94 ; \mathrm{TLI}=0.93$ ) (Sheldrick et al., 2012). The Brazilian Portuguese version of the PPSC uses a different 3-factor model that is more suitable to the Brazilian population. Nevertheless, the 
unifactorial model has shown better results, as the use of its total score (RMSEA $=.02$, CFI $=.98$, TLI $=.98$ ) has a Cronbach's alpha of $\alpha=.81$ (Moreira et al., 2019).

Rolim et al. (2019) concluded that the PPSC is a useful measurement in the realm of child development analysis, especially for social-emotional and behavioral screenings of young children. It is an instrument that is usable in large scale studies, is reliable, low cost, easy to use, and has a high diagnostic precision. Therefore, this study aimed to analyze: (1) the psychometric properties of the Portuguese version of the PPSC through using a Confirmatory Factor Analysis (CFA) to examine its factor structure and (2) the differences between groups concerning their sociodemographic characteristics.

\section{METHOD}

The present study is quantitative, cross-sectional descriptive and empirical, with a simple retrospective investigation plan. It is also an instrumental study, because it aims to assess the psychometric characteristics of a measure (Montero \& Léon, 2007).

\section{Participants}

A total of 398 parents of children aged 18 to 60 months $(M=39.25$; $S D=13.23)$, from different regions of Portugal, agreed to participate in this study. Most of the participants were mothers (87.90\%) and were married (81.90\%), with an age range of 22 to 49 years $(M=36.65 ; S D=4.63)$. Of the children, $54.80 \%$ were boys and $45.20 \%$ were girls. Concerning the participants' educational levels, $64.80 \%$ had university level qualifications, $29.60 \%$ had finished high school, and $5.50 \%$ had finished elementary school. The majority of the parents were employed (87.20\%).

\section{Measures}

The PPSC is a brief social-emotional screening instrument for children aged 18 to 60 months. It consists of an 18-item questionnaire as described previously.

Sociodemographic characteristics were collected with a self-report questionnaire that asked for the following data: the children and parents' ages, their gender, their marital status, their work status, as well as the qualification and educational levels of the participating parents.

\section{Procedure}

The authorization to use and translate the PPSC scale was obtained directly from its authors (Sheldrick et al., 2012), as well as from the Office of Technology Development from Boston University. The original measurement was translated by a professional English-Portuguese translator. During the translation and retroversion processes, appropriate procedures (e.g., avoiding item bias or differential item functioning) were followed. The final version was then presented to a panel of five participants with the sample criteria given to them to assess for any errors or difficulties in using this instrument.

The sample was selected for convenience using the snowball method. The first author asked the recruited participants to contact other potential respondents that they might know of. The final dataset collected consisted of a total of 398 respondents. Data collection took place online, with Google Forms, during the month of May 2020. The study was approved by the Ethics Committee of ARS Algarve I.P.. Parental informed consent was previously obtained from all the participants who had agreed to collaborate in this study. Participation was voluntary and no compensation was offered.

\section{Data analysis}

The data was analyzed using SPSS and AMOS software (v.20 IBM SPSS Inc. Chicago, IL.). First, a descriptive analysis of the sociodemographic variables was performed, which revealed the overall sample size, percentages, means, and standard deviations according to each type of variable.

The factor structure of the Portuguese version of the PPSC was assessed using a CFA with the Maximum Likelihood method. Fit indices were then calculated, including the following analysis: ChiSquare/Degrees of Freedom ( $\chi 2 / \mathrm{df})$ with desirable values between 1 and 2 . Regarding the incremental fit index (Bollen's IFI), values that exceeded .90 were regarded as acceptable. Furthermore, a Root Mean Square Error of Approximation (RMSEA) was used with a desirable value being set as one that is below .05 and which was acceptable until a value of .08. Additionally, Bentler's Comparative Fit Index (CFI) was utilized with an acceptance value of .90 or greater (Abad et al., 2011). We also used the Akaike Information Criterion (AIC) to select the models with the lowest expected discrepancy between the true and hypothesized models (West et al., 2014). 
The PPSC's internal structure was then analyzed through the use of descriptive statistics, Cronbach's alpha, and Pearson's correlation values between the items and factors. Finally, an ANOVA and Pearson's correlation analysis were conducted with the sociodemographic variables and the scale.

\section{RESULTS}

\section{PPSC confirmatory factor analysis}

The PPSC was first analyzed as a unifactorial scale via a CFA operating with the Maximum Likelihood method. The original 4-factor structure of the 18-item scale was analyzed using the same method. Finally, the original alternative 3-factor model, consisting of 12 items, was also tested. The goodness of fit for the different model indices tested are displayed in Table 1. The unifactorial and the 3-factor models demonstrated acceptable values; however, the originally proposed unifactorial model had the best fit.

Table 1. Goodness of Fit Indices for Different ML Models of PPSC

\begin{tabular}{lccccc}
\hline PPSC & $\chi \mathbf{2} / \mathbf{d f}$ & IFI & RMSEA (90\% CI) & CFI & AIC \\
\hline Unifactorial Model & 1.35 & .97 & $.03(.02-.04)$ & .97 & 266.04 \\
4-factor ModeI & 2.44 & .86 & $.06(.05-.07)$ & .85 & 396.61 \\
3-factor Model & 1.92 & .94 & $.05(.03-.06)$ & .93 & 151.88 \\
\hline
\end{tabular}

Note. $\mathrm{ML}=$ Maximum likelihood; $\chi 2 / \mathrm{df}=$ chi-square/degrees of freedom; $I F I=$ incremental fit index; $R M S E A=$ Root Mean Square Error of Approximation; $C F I$ = Bentler's Comparative Fit Index; AIC = Akaike Information Criterion; $\mathrm{CI}=$ Confidence Interval.

The unifactorial model does not justify changes to the original scales. Fit indices show a $\chi 2 / \mathrm{df}$ between 1 and 2, an IFI above .9, a RMSEA below .05, a CFI above .9, and an improved AIC in the 4 -factor model. Despite item six having a lower standardized loading value, its removal does not improve the overall goodness of the Model Fit or its Cronbach's Alpha value. Additionally, the relevance of the content of this question justifies keeping it in this instrument. All items inside each factor with modification indices were included as covariates, improving the model fit indices. The standardized loadings of the unifactorial model are displayed in Table 2.

Table 2. Standardized Factor Loadings of the Unifactorial Model for the PPSC and Descriptive Statistics

\begin{tabular}{clc}
\hline PPSC Items & Factor \\
\hline 1 & Does your child break things on purpose? & .30 \\
2 & Does your child fight with other children? & .37 \\
3 & Is your child aggressive? & .35 \\
4 & Is your child angry? & .27 \\
5 & Does your child have trouble playing with other children? & .19 \\
6 & Does your child seem sad or unhappy? & .04 \\
7 & Does your child seem nervous or afraid? & .35 \\
8 & Does your child get upset if things are not done in a certain way? & .53 \\
9 & Does your child have a hard time with change? & .41 \\
10 & Does your child have trouble paying attention? & .54 \\
11 & Is your child fidgety or unable to sit still? & .48 \\
12 & Does your child have trouble staying with one activity? & .52 \\
13 & Is it hard to take your child out in public? & .43 \\
14 & Is it hard to get your child to obey you? & .57 \\
15 & Is it hard to comfort your child? & .54 \\
16 & Is it hard to know what your child needs? & .32 \\
17 & Is it hard to keep your child on a schedule or routine? & Does your child have a hard time calming down? \\
\hline
\end{tabular}




\section{BPSC internal structure}

Table 3 displays the Cronbach's alphas of the unifactorial and the 3-factor models with their subscales. The value for the total instrument was $\alpha=.80$, which is lower than the $\alpha=.88$ and $\alpha=.86$ of the original scale, but is similar to the $\alpha=.81$ of the Brazilian translation. The 3-factor model demonstrated an unacceptable $\alpha$ value in the "Internalizing" and "Externalizing" subscales ( $\alpha=.45$ and $\alpha=.57$, respectively) (Moreira et al., 2019; Sheldrick et al., 2012). There was no improvement found in the Cronbach's alphas following the removal of any of the scale's items. Table 3 shows the descriptive statistics of the PPSC's 18-item unifactorial model, with Table 4 showing the inter-item correlations of the items in this scale, as well as the mean, standard deviation, skewness and kurtosis of each item.

Table 3. PPSC Cronbach's Alpha, Mean Inter-Item Correlations, Corrected Item-Total Correlation Range

\begin{tabular}{lcccc}
\hline & N of Items & $\boldsymbol{\alpha}$ & MIIC & CITCR \\
\hline Unifactorial model & 18 & .80 & .18 & $-.07-.55$ \\
3-factor model - Total & 12 & .70 & .15 & $-.07-.55$ \\
3-factor model - Internalizing & 5 & .45 & .14 & $.04-.28$ \\
3-factor model - Externalizing & 4 & .57 & .26 & $.11-.39$ \\
3-factor model - Attention problems & 3 & .75 & .51 & $.49-.55$ \\
\hline
\end{tabular}

Note. PPSC = Preschool Pediatric Symptom Checklist; MIIC = Mean Inter-Item Correlation; CITCR = Corrected Item-Total Correlation Range. 
Table 4. PPSC Pearson's Correlation Matrix and Descriptive Statistics

\begin{tabular}{|c|c|c|c|c|c|c|c|c|c|c|c|c|c|c|c|c|c|c|}
\hline Items & 1 & 2 & 3 & 4 & 5 & 6 & 7 & 8 & 9 & 10 & 11 & 12 & 13 & 14 & 15 & 16 & 17 & 18 \\
\hline PPSC_1 & - & & & & & & & & & & & & & & & & & \\
\hline PPSC_2 & $.29^{* *}$ & - & & & & & & & & & & & & & & & & \\
\hline PPSC_3 & $.29^{* *}$ & $.39^{* *}$ & - & & & & & & & & & & & & & & & \\
\hline PPSC_4 & $.16^{* *}$ & $.11^{*}$ & $.32^{* *}$ & - & & & & & & & & & & & & & & \\
\hline PPSC_5 & -.04 & .05 & .05 & -.07 & - & & & & & & & & & & & & & \\
\hline PPSC_6 & -.01 & -.03 & .05 & $.14^{* *}$ & .07 & - & & & & & & & & & & & & \\
\hline PPSC_7 & .00 & -.01 & .08 & $.25^{* *}$ & $.16^{* *}$ & $.25^{* *}$ & - & & & & & & & & & & & \\
\hline PPSC_8 & $.23^{* *}$ & $.21^{* *}$ & $.17^{* *}$ & .07 & .09 & .04 & $.18^{* *}$ & - & & & & & & & & & & \\
\hline PPSC_9 & .08 & $.12^{*}$ & $.13^{* *}$ & $.18^{* *}$ & .08 & .05 & $.20^{* *}$ & $.28^{* *}$ & - & & & & & & & & & \\
\hline PPSC_10 & $.17^{* *}$ & $.18^{* *}$ & $.18^{* *}$ & $.17^{* *}$ & $.14^{* *}$ & .07 & $.19^{* *}$ & $.27^{* *}$ & $.23^{* *}$ & - & & & & & & & & \\
\hline PPSC_11 & $.15^{* *}$ & $.14^{* *}$ & $.12^{*}$ & .08 & .10 & .01 & $.18^{* *}$ & $.28^{* *}$ & $.13^{*}$ & $.49^{* *}$ & - & & & & & & & \\
\hline PPSC_12 & $.15^{* *}$ & $.14^{* *}$ & $.18^{* *}$ & -.02 & $.18^{* *}$ & -.01 & $.16^{* *}$ & $.28^{* *}$ & $.21^{* *}$ & $.55^{* *}$ & $.49^{* *}$ & - & & & & & & \\
\hline PPSC_13 & $.14^{* *}$ & $.20^{* *}$ & $.13^{* *}$ & .08 & $.10^{*}$ & -.03 & .06 & $.20^{* *}$ & $.19^{* *}$ & $.27^{* *}$ & $.24^{* *}$ & $.25^{* *}$ & - & & & & & \\
\hline PPSC_14 & $.21^{* *}$ & $.22^{* *}$ & $.23^{* *}$ & $.16^{* *}$ & $.01^{*}$ & -.04 & $.16^{* *}$ & $.33^{* *}$ & $.23^{* *}$ & $.24^{* *}$ & $.28^{* *}$ & $.29^{* *}$ & $.25^{* *}$ & - & & & & \\
\hline PPSC_15 & $.20^{* *}$ & $.25^{* *}$ & $.25^{* *}$ & $.21^{* *}$ & .09 & .04 & $.24^{* *}$ & $.23^{* *}$ & $.21^{* *}$ & $.20^{* *}$ & $.21^{* *}$ & $.23^{* *}$ & $.28^{* *}$ & $.29^{* *}$ & - & & & \\
\hline PPSC_16 & $.12^{*}$ & $.18^{* *}$ & $.21^{* *}$ & $.23^{* *}$ & .07 & $.18^{* *}$ & .09 & $.17^{* *}$ & $.22^{* *}$ & $.14^{* *}$ & $.10^{*}$ & $.18^{* *}$ & $.14^{* *}$ & $.14^{* *}$ & $.30^{* *}$ & - & & \\
\hline PPSC_17 & .07 & $.11^{*}$ & .07 & $.15^{* *}$ & .07 & .08 & $.19^{* *}$ & $.16^{* *}$ & $.16^{* *}$ & $.31^{* *}$ & $.23^{* *}$ & $.21^{* *}$ & $.17^{* *}$ & $.26^{* *}$ & $.23^{* *}$ & $.22^{* *}$ & - & \\
\hline PPSC_18 & $.20^{* *}$ & $.28^{* *}$ & $.24^{* *}$ & $.18^{* *}$ & $.14^{* *}$ & .03 & $.30^{* *}$ & $.37^{* *}$ & $.23^{* *}$ & $.42^{* *}$ & $.34^{* *}$ & $.26^{* *}$ & $.25^{* *}$ & $.38^{* *}$ & $.39^{* *}$ & $.15^{* *}$ & $.24^{* *}$ & - \\
\hline$M$ & .20 & .12 & .09 & .04 & .11 & .07 & .26 & 1.07 & .47 & .64 & .71 & .57 & .11 & .52 & .10 & .12 & .30 & .48 \\
\hline$S D$ & .43 & .33 & .29 & .20 & .33 & .26 & .48 & .52 & .57 & .62 & .65 & .58 & .33 & .56 & .32 & .32 & .49 & .54 \\
\hline$S$ & 1.96 & 2.34 & 2.81 & 4.54 & 3.19 & 3.97 & 1.57 & .09 & .71 & .42 & .38 & .44 & 2.91 & .46 & 3.13 & 2.38 & 1.26 & .48 \\
\hline$K$ & 2.98 & 3.49 & 5.95 & 18.71 & 10.09 & 15.82 & 1.48 & .58 & -.52 & -.66 & -.74 & -.70 & 7.93 & -.84 & 9.49 & 3.66 & .45 & -.93 \\
\hline
\end{tabular}




\section{PPSC and sociodemographic variables}

There were no significant correlations found between the PPSC and parents' age (PPSC unifactorial Model: $r=-.02 ; p=.744$ ) or the children's age (PPSC unifactorial Model: $r=.05 ; p=.371$ ). As seen in the participants' descriptions, the relevant differences between the group sizes in some of the sociodemographic variables did not allow for the conducting of a reliable comparison, meaning that only groups with similar characteristics were compared. Regarding the other sociodemographic variables used in this study, children's gender and parents' education level held no significant correlations with the PPSC (Table 5).

Table 5. Differences between Sociodemographic Variables and the PPSC Models

\begin{tabular}{lccccc}
\hline Level of Education & $\begin{array}{c}\text { From Elementary } \\
\text { to High School } \\
(\mathbf{N = 1 4 0 )}\end{array}$ & $\begin{array}{c}\text { University } \\
\mathbf{( N = 2 5 8 )}\end{array}$ & $\boldsymbol{F}$ & $\boldsymbol{p}$ & $\boldsymbol{\eta} \mathbf{2}$ \\
PPSC Unifactorial Model & $5.72(3.69)$ & $6.12(4.02)$ & 0.95 & .331 & .00 \\
\hline Child's gender & $\begin{array}{c}\text { Male } \\
(\mathbf{N}=\mathbf{2 1 8})\end{array}$ & $\begin{array}{c}\text { Female } \\
(\mathbf{N}=\mathbf{1 8 0})\end{array}$ & $\boldsymbol{F}$ & $\boldsymbol{p}$ & $\boldsymbol{\eta} 2$ \\
PPSC Unifactorial Model & $5.95(3.76)$ & $6.01(4.08)$ & 0.02 & .885 & .00 \\
\hline
\end{tabular}

\section{DISCUSSION}

This study aimed to translate the 18-item PPSC into Portuguese, building on the research of Sheldrick et al. (2012), while also analyzing the structural validity and internal consistency of the developed Portuguese version of the PPSC in a sample of Portuguese parents. The CFA confirmed that the Portuguese version of the unifactorial PPSC possesses good psychometric properties without any modification from the original scale, which follows the initial recommendation put forward.

The internal structure of the Portuguese version of the PPSC, in its unifactorial model, presents a reliable Cronbach's alpha of $\alpha=.80$ (Kaplan \& Saccuzzo, 2013). This was lower than the $\alpha=.88$ and $\alpha=.86$ values of the original scale, but similar to that of the $\alpha=.81$ in the Brazilian translation (Moreira et al., 2019; Sheldrick et al., 2012). The model fit indices of our sample show an improvement when compared to the original unifactorial scale $($ RMSEA $=0.08 ; \mathrm{CFI}=0.94 ; \mathrm{TLI}=0.93$ ) and are similar to the Brazilian translation (RMSEA $=0.02 ;$ CFI $=0.98$; TLI $=0.98$ ), as they present good values when examining this measure's consistency $(\chi 2 / d f=1.35 ;$ IFI $=.97 ;$ RMSEA = .03; CFI = .97; AIC $=266.04)$, resulting in us adopting the unifactorial model (Moreira et al., 2019; Sheldrick et al., 2012). Although the 3-factor model demonstrated good values in the model fit indices, the alpha values of the "Internalizing" and "Externalizing" subscales were below the acceptable limit (Kaplan \& Saccuzzo, 2013). Adequate homogeneity was present between most of the items, with the mean inter-item correlations falling within the recommended value range of .15-.50 (Clark \& Watson 1995). Regarding the corrected item-total correlation range, most of our results were above the minimum recommended value of .20 for each factor (Nunnally \& Bernstein, 1994).

No significant associations were found between the PPSC and the sociodemographic variables included in this study. Previous studies have related certain behavioral and social-emotional challenges in children with their parents' marital status, the overall family atmosphere, their cultural context, experiences around stressful events, and their cognitive skills (Mitchell \& Hauser-Cram, 2009; Tichovolsky, 2011). In this study, only the marital status of the children's parents was considered, but the sample was extremely heterogeneous in terms of its statistical reliability. In order to ensure the validity of the use of the measure in different contexts, Sheldrick et al. (2012) regressed the original PPSC latent variables on six covariates, parent education (high school education or less versus education beyond high school), ethnicity (Hispanic versus not), race (white versus non-white), child gender (male versus female), the child's age (18 months -3 years versus $>3$ years), and enrollment site (primary care versus referral clinic). However, the relation between them and the PPSC wasn't reported.

The social-emotional competencies and behavioral problems of small children is a frequent issue, as reported in several studies in different countries, but with values within 5\% to 44\% (Briggs-Gowan et al., 2001; Klein et al., 2019; Nunes \& Ayala, 2011; 2013; Peralta-Carcelen et al., 2017; Sim et al., 2019), being this difference possibly related not only with cultural matters but also with different measures. Even so, parents' perception of potential problems tends to be lower (Alakortes et al., 2017; Briggs-Gowan et al., 2001).

So, as stated by Alakortes et al. (2017) and Silva et al., (2019), the early detection of social-emotional problems faced by children is extremely important, and this measure allows healthcare professionals to predict developmental and behavioral disorders, to enable early intervention. The PPSC has the additional benefits of being freely available, brief, easy to read, and easy to score, and is also suitable for tracking children's behavior across the age range (Sheldrick et al., 2012). 
The present study did have several limitations that should be considered. First, the generalizability of the sample may not be high, as it was gathered via a convenience sampling approach, which means that the specific sociodemographic group of this study's participants may not be representative of the wider population. Additionally, there was a large difference in the study sample between participants' gender, as it included mostly mothers; with the educational level of the participants mostly being at a university level. Another limitation was the cross-sectional nature of the research design, which does not allow for the examination of temporal stability or a test-retest analysis. In future, other variables should be considered in order to develop a better understanding of the social-emotional challenges faced by children and their causes. Although the measure detects these problems early in children, appropriate intervention strategy is not discussed or suggested, which could be taken in consideration in future studies. Finally, the data collection was conducted during a period of pandemic-induced confinement, with many people being instructed to stay at home. This unique development may, therefore, have misrepresented the perceptions of the children's behaviors.

\section{CONCLUSION}

Our findings support the viability of the Portuguese version of the unifactorial PPSC in Portugal, as they reveal that the measure has acceptable psychometric properties in this context.

Despite these results, some study limitations must be taken into account, as mentioned previously. Although the PPSC has good psychometric properties, and the reliability analyses have revealed that this questionnaire is suitable for use among the Portuguese population, future studies are still needed to retest the Portuguese version of the PPSC in a real primary healthcare consultation environment, as well as in a larger and more heterogeneous sample. Moreover, in future studies other convergent and discriminant measures should be used to reduce the social desirability phenomenon. It would also be advisable to expand the sample to include Portuguese families from all regions of the country and include more parents. At the same time, it would be interesting to explore differences between different samples (at-risk and community samples) and to consider the possible variability of the scale in different family compositions (e.g., two-parent, single-parent, reconstituted).

The second aim of this study was to analyze the associations between the sociodemographic characteristics of the participants and the PPSC. None were found between these two variables.

In summation, the PPSC has been proven to be an easy to use and reliable screening measure for social-emotional and behavioral challenges among children aged 18 to 60 months, as well as in pediatric primary healthcare settings. The use of the PPSC can be a predictive measure for anticipating developmental difficulties in young children and, with this study, it is now suitable to be used in Portugal, which can be a huge benefit to children's evaluation in a pediatric consultation and in future studies.

\section{REFERENCES}

Abad, F., Olea, J., Ponsoda, V., \& Garcia, C. (2011). Medición en ciencias sociales y de la salud [Measurement in health and social sciences]. Editorial Sintesis.

Abidin, R. (1995). Parenting stress index. Professional manual (3rd ed.). Psychological Assessment Resources.

Alakortes, J., Kovaniemi, S., Carter, A. S., Bloigu, R., Moilanen, I., \& Ebeling, H. (2017). Do child healthcare professionals and parents recognize social-emotional and behavioral problems in 1-year-old infants? European Child \& Adolescent Psychiatry, 26, 481-495. https://doi.org//10.1007/s00787016-0909-3

Briggs-Gowan, M. J., \& Carter, A. S. (1998). Preliminary acceptability and psychometrics of the infanttoddler social and emotional assessment (ITSEA): A new adult-report questionnaire. Infant Mental Health Journal, 19, 422-445. https://doi.org/10.1002/(SICI)1097-0355(199824)19:4<422::AIDIMHJ5>3.0.CO;2-U

Briggs-Gowan, M. J., Carter, A. S., Skuban, E. M., \& Horwitz, S. M. (2001). Prevalence of social emotional and behavioral problems in a community sample of 1- and 2-year-old children. Journal of the American Academy of Child and Adolescent Psychiatry, 40, 811-819. https://doi.org/10.1097/00004583200107000-00016

Clark, L. A., \& Watson, D. B. (1995). Constructing validity: basic issues in objective scale development. Psychological Assessment, 7, 309-319. https://doi.org/10. 1037/1040-3590.7.3.309

Finello, K. M., \& Poulsen, M. K. (2018). Behavioral Assessment of Baby's Emotional \& Social Style (BABES) Toolkit: Intervention Strategies for Developmental Guidance \& Support. WestEd

Greenspan, S. I. (2004). Greenspan Social-Emotional Growth Chart. Harcourt Assessment. 
Halperin, J.M., \& Marks, D.J. (2019). Practitioner Review: Assessment and treatment of preschool children with attention-deficit/hyperactivity disorder. Journal of Child Psychology and Psychiatry, 60, 930943. https://doi.org/10.1111/jcpp.13014

Halperin, J.M., \& Marks, D.J. (2019). Practitioner Review: Assessment and treatment of preschool children with attention-deficit/hyperactivity disorder. Journal of Child Psychology and Psychiatry, 60, 930943. https://doi.org/10.1111/jcpp.13014

Jahromi, L. B., Bryce, C. I., \& Swanson, J. (2013). The importance of self-regulation for the school and peer engagement of children with high-functioning autism. Research in Autism Spectrum Disorders, 7, 235246. https://doi.org/10.1016/j.rasd.2012.08.012

Kaplan, R., \& Saccuzzo, D. (2013). Psychological Testing: Principles, Applications, and Issues (8th ed). Cengage Learning

Klein, A., Schlesier-Michel, A., Otto, Y., White, L., Andreas, A., Sierau, S., Bergmann, S., Perren, S., \& Von Klitzing, K. (2019). Latent trajectories of internalizing symptoms from preschool to school age: A multi-informant study in a high-risk sample. Development and Psychopathology, 31, 657-681. https://doi.org/10.1017/S0954579418000214

Linberg, A., Burghardt, L., Freund, J. D., \& Weinert, S. (2020). Differential effect of duration of early childcare under the age of three on social-emotional outcomes. Early Child Development and Care, 190, 25052519. https://doi.org/10.1080/03004430.2019.1588891

Mingebach, T., Kamp-Becker, I., Christiansen, H., \& Weber L. (2018). Meta-meta-analysis on the effectiveness of parent-based interventions for the treatment of child externalizing behavior problems. PLoS One, 13, e0202855. https://doi.org/10.1371/journal.pone.0202855

Montero, I., León, O. G. (2007). A guide for naming research studies in Psychology. International Journal of Clinical and Health Psychology, 7(3), 847-862

Moreira, R. S., Magalhães, L. C., Siqueira, C. M., \& Alves. C. R. L. (2019). Cross-cultural adaptation of the child development surveillance instrument "Survey of Wellbeing of Young Children (SWYC)" in the Brazilian context. Journal of Human Growth and Development, 29, 28-38. https://doi.org/10.7322/jhgd.145001

Nunes, C., \& Ayala, A. (2013). ¿Consejo o prescripción? Análisis de las recomendaciones pediátricas en las consultas del programa del niño sano [Advice or prescription? Analysis of the pediatric recommendations in the healthy child program visits]. Revista de Pediatría de Atención Primaria, 15, e135-e143. http://scielo.isciii.es/pdf/pap/v15n60/original1.pdf

Nunes, C., \& Ayala, M. (2011). ¿De qué hablan los pediatras y las madres en la consulta de seguimiento de la salud infantil? [What do pediatricians and mothers talk about in the well-child program visits?]. Anales de Pediatría, 75, 239-246. https://doi.org/10.1016/j.anpedi.2011.03.020

Nunnally, J., \& Bernstein, I. (1994). Psychometric theory (3rd ed.). McGraw-Hill.

Ortiz, R. M. R. \& Barnes, J. (2019). Temperament, parental personality and parenting stress in relation to social-emotional development at 51 months. Journal Early Child Development and Care, 189, 19781991. https://doi.org/10.1080/03004430.2018.1425297

Peralta-Carcelen, M., Carlo, W. A., Pappas, A., Vaucher, Y. E., Yeates, K. O., Phillips, V. A., Gustafson, K. E., Payne, A. H., Duncan, A. F., Newman, J. E., \& Bann, C. M. (2017). Behavioral problems and socialemotional competence at 18 to 22 months of extremely premature children. Pediatrics, 139, e20161043. https://doi.org/10.1542/peds.2016-1043

Perrin, E. C., Sheldrick, R. C., Visco, Z., \& Mattern, K. (2016). The survey of well-being of young children (SWYC) user's manual. Floating Hospital for Children at Tufts Medical Center. https://www.tuftschildrenshospital.org/The-Survey-of-Wellbeing-of-Young-Children/ManualTraining-Resources

Rolim, L. Amaral, J. \& Leite, A. (2019). Instrumentos que avaliam o vínculo materno e os riscos de alteração no desenvolvimento infantil [Instruments that validate or maternal bond and the risks of alteration or child development]. International Journal of Developmental and Educational Psychology INFAD, 2, 35-44. http://www.infad.eu/RevistaINFAD/OJS/index.php/IJODAEP/article/view/1736/1535

Sheldrick, R. C., Henson, B. S., Neger, E. N., BA; Merchant, S., \& Murphy, J. M. (2012). The preschool pediatric symptom checklist (PPSC): Development and initial validation of a new social/emotional screening instrument. Academic Pediatrics, 12, 456-467. https://doi.org/10.1016/j.acap.2012.06.008

Silva, D. I., Mello, D. F., Mazza, V. A., Toriyama, A. T. M., \& Veríssimo, M. L. Ó. R. (2019). Dysfunctions in the socio emotional development of infants and its related factors: an integrative review. Texto Contexto Enfermagem, 28, e20170370. https://doi.org/10.1590/1980-265X-TCE-2017-0370

Sim, F., Thompson, L., Marryat, L., Ramparsad, N., \& Wilson, P. (2019). Predictive validity of preschool screening tools for language and behavioural difficulties: A PRISMA systematic review. PLoS ONE, 14, e0211409. https://doi.org/10.1371/journal.pone.0211409 
Squires, J., Bricker, D. D., \& Potter, L. (1995). Ages and stages questionnaires user's guide. Brookes Publishing Company.

West, S., Taylor, A., \& Wu, W. (2012). Model fit and model selection in structural equation modeling. In R. Hoyle (Ed.). Handbook of structural equation modeling (pp. 209-231). The Guilford Press.

Yoon, S., Yoon, D., Wang, X., Tebben, E., Lee, G., \& Pei, F. (2017). Co-development of internalizing and externalizing behavior problems during early childhood among child welfare-involved children. Children and Youth Services Review, 82, 455-465. https://doi.org/10.1016/j.childyouth.2017.10.016

$\begin{array}{ll}\text { Historial do artigo } & \\ \text { Recebido } & 11 / 04 / 2021 \\ \text { Aceite } & 10 / 08 / 2021 \\ \text { Publicado } & 20 / 12 / 2021\end{array}$

